\title{
A Festschrift to Honour Jim Greer: Guest Editors' Introduction, Part 2
}

\section{A Special Issue of the International Journal of Artificial Intelligence in Education}

\author{
Gord McCalla ${ }^{1} \cdot$ Julita Vassileva $^{1}$ \\ Published online: 19 October 2021 \\ (C) International Artificial Intelligence in Education Society 2021
}

This issue of the International Journal of Artificial Intelligence in Education is part 2 of a special issue of the journal, a Festschrift honouring our former colleague and friend, Jim Greer. Jim was a well-known figure in the international AIED research community who passed away recently. With 24 papers dedicated to Jim's memory this Festschrift is a tribute not only to his legacy, but also to his ongoing influence on the field. 11 papers appeared in the previous issue of the journal (volume 31, issue 3 ). The current issue of the journal (volume 31, issue 4) contains the other 13 papers.

Volume 31, issue 3, includes a guest editors' introduction to the special issue that is a full biography of Jim and a summary of all 24 papers in the Festschrift. Each paper, depending on its principal focus, has been slotted into one of five topics that roughly track Jim's changing research interests during his long career. Part 1 contains papers with a focus on learner modelling and personalization (7 papers) and evaluation (4 papers), Jim's early interests. Part 2 contains papers reflecting his later interests in peer learning, collaboration, and the social dimension ( 3 papers), privacy ( 2 papers), and learning analytics and educational data mining (8 papers).

We are very pleased to be able to present to the AIED community this second part of the Festschrift honouring Jim. We hope that both parts will provide many stimulating insights, and trigger happy memories of Jim and his generous support and encouragement of so many people over the years. Surely, the most fitting way to conclude the Festschrift is with a toast to Jim. So, if you so desire, please raise a glass of single malt (Jim's favourite tipple) or your own beverage of choice: thanks, Jim, for your great contributions to AIED and to the AIED community.

Publisher's Note Springer Nature remains neutral with regard to jurisdictional claims in published maps and institutional affiliations.

Gord McCalla

mccalla@cs.usask.ca

Julita Vassileva

jiv@cs.usask.ca

1 Department of Computer Science, University of Saskatchewan, Saskatoon, SK S7N 5C9, Canada 